\title{
What "Moves" the Populations Most Likely to Be Physically Inactive-Women and Older Adults? Evidence From Mueller, a Mixed-Use Neighborhood in Austin, Texas
}

\author{
Tamara Vehige Calise, William DeJong, Timothy Heren, Chloe Wingerter, and Harold W. Kohl III
}

\begin{abstract}
Background: Older age groups are less likely than their younger counterparts to be regularly active and women are even less active. Ecological models suggest that multiple levels of influence with each level influencing the next level impacts physical activity behaviors. Methods: Hierarchical multiple regressions were used to determine factors within and across the ecological model that predicted both total physical activity and walking for recreation. Findings: The overall predictors of total physical activity were different than those of walking for recreation, with the exception of dog ownership and perceived barriers. Gender and age were significant predictors of walking for recreation, but these associations were not present for total physical activity. Women and older adults walked more for recreation in a mixed-use community, Mueller, (and thus engaged in more total physical activity) compared with men and younger adults. Conclusion: Behavior-specific physical activity as well as total physical activity led to a better understanding of factors that may impact behavior among an overall aging population, especially women. This level of specificity is important in understanding specific factors that are associated with physical activity among vulnerable populations and can help guide the development of tailored, cost-effective, and efficient policies and interventions.
\end{abstract}

Keywords: physical activity, vulnerable populations, built environment

The population of US adults aged 65 years and older has increased by $25 \%$ between 2003 and 2013 and is projected to more than double to 98 million in 2060. ${ }^{1}$ In 2011, "baby boomers" or individuals born between 1946 and 1964 began turning 65 years of age and are now driving growth at the older ages of the population. ${ }^{2}$ Persons reaching age 65 have an average life expectancy of an additional 19.3 years (20.5 y for women and $17.9 \mathrm{y}$ for men). ${ }^{1}$ Although improved healthcare has led to a progressively increasing life expectancy among older adults, studies suggest baby boomers have higher rates of chronic disease, more disability, and lower self-rated health than members of the previous generation at the same age. ${ }^{3}$ Moreover, $28 \%$ of noninstitutionalized older persons live alone, which is 8.8 million women and 3.8 million men. ${ }^{1} \mathrm{By}$ 2056, the population aged 65 years and older will be larger than those youth under 18 years $^{2}$ suggesting the importance of improving this population's health status.

A physically active lifestyle has many health benefits. Individuals who engage in regular physical activity have a lower risk of chronic disease and premature death. ${ }^{4}$ Walking, in particular, has been identified as a low-cost, aerobic physical activity that people of all ages can perform. ${ }^{5}$ Walkers are more likely to meet or exceed physical activity guidelines. ${ }^{6}$ Numerous studies looking at the impact of walking have found a reduced risk of cardiovascular disease, weight loss, ${ }^{7}$ and blood pressure control. ${ }^{8}$

Evidence increasingly indicates that physical activity can extend years of active independent living, reduce disability, and improve the quality of life for older people. ${ }^{4}$ Yet, older age groups (60 y and older) are less likely than their younger counterparts

Calise and Wingerter are with Healthy Communities, John Snow Inc (JSI), Boston, MA, USA. DeJong and Heren are with the Boston University School of Public Health, Boston, MA, USA. Kohl is with the School of Public Health, University of Texas Health Science Center - Houston, Houston, TX, USA; and The University of Texas, Austin, TX, USA. Calise (tcalise@jsi.com) is corresponding author. to be regularly active, and women are less likely than men to achieve regular physical activity, especially leisure-time physical activity. ${ }^{9}$

Although individual-level factors likely influence physical activity behaviors, research suggests that recreational walking, in particular, may also be influenced by societal and environmental forces that support a safe, enjoyable, and social experience. ${ }^{10,11}$ Ecological models suggest that multiple levels of influence (individual, interpersonal, etc), with each level influencing the next, impacts physical activity behaviors. ${ }^{12}$ Although the levels of the social-ecological model will remain the same, the specific factors within each level will vary depending on the population group. ${ }^{13}$ In this way, physical activity behavior is complex. Understanding factors that influence older adults' physical activity levels, specifically walking, can help inform strategies to increase their likelihood of achieving the recommended amount of activity and ultimately improve older adult health.

Data from the parent Healthy Austin Study ${ }^{14}$ provide a unique opportunity to specify factors across multiple levels of the socialecological model that may influence, or be influenced by, factors known to impact physical activity. The targeted community offered neighborhood characteristics positively associated with recreational physical activity including aesthetics and social interaction opportunities, ${ }^{15-17}$ safety, ${ }^{18,19}$ and access to outdoor recreational facilities, including trails. ${ }^{15,20-22}$ This current study looked at these factors within and across the ecological model, including individual and household characteristics, to better understand physical activity levels.

Associations between the environment and physical activity are thought to become more understood when behaviors and contexts are specifically examined. ${ }^{14,23}$ As such, this study looked at both total postmove physical activity as well as walking for recreation inside the neighborhood. Findings could help guide the development of tailored, cost-effective, and efficient policies and 
interventions. This may be especially important in increasing activity levels among our least active, but growing the older adult population.

\section{Methods}

The study was approved by the institutional review boards in both the Boston University Medical Center and the University of Texas Health Science Center in Houston.

\section{Population Parent Study}

This study was based on data from the Healthy Austin Study, ${ }^{14}$ which included a cross-sectional survey of participants who had recently moved to a New Urbanist-inspired neighborhood (Mueller) in Austin, Texas. Briefly, a survey was mailed to all households as of April 1, 2009, to assess individual and household characteristics, perceived neighborhood features, and health behaviors.

\section{Procedures}

The methods used for the recruitment and data collection procedures for the Healthy Austin Study have been published elsewhere. ${ }^{14}$ Briefly, a mailback survey was sent to all households occupied as of April 1, 2009 (per public utility company records), and 1 adult per household was invited to participate in the study. Participants provided consent to participate and completed a questionnaire on their individual and household characteristics, neighborhood characteristics, and health behaviors. A subset of questions, including neighborhood characteristics and physical activity behaviors, were asked in relation to their current neighborhood and in relation to their prior neighborhood (ie, the neighborhood they lived in before moving to Mueller). Of the 424 surveys mailed, 267 were returned (63.4\% response).

\section{Current Study Design}

This study focused on better understanding factors associated with adults' physical activity behaviors, specifically those related to older adults. Hierarchical multiple regressions (HMR) were used to determine factors within and across the ecological model that predicted both total physical activity and walking for recreation.

\section{Measures}

Physical Activity. The Neighborhood Physical Activity Questionnaire was used to measure physical activity, which was based on a valid instrument (International Physical Activity Questionnaire-short version), ${ }^{24}$ and has been found to be reliable. ${ }^{25}$ The present study examined both total physical activity (total time spent walking, biking, and engaging in other moderate- and vigorousintensity recreational and transport-related activities) inside and outside the neighborhood and walking for recreation inside the neighborhood. As per the 2008 Physical Activity Guidelines for Americans, ${ }^{26}$ a measure of duration, reported as minutes per week, was used for each variable (eg, "In a usual week, how many times did you walk for recreation, health, or fitness (including walking your dog) IN OR AROUND your neighborhood or local area?").

Individual, Household, Health, and Behavioral Variables. Individual- and household-level information included sex; age; education; race; income; length of residency in Mueller ( $\leq 5 \mathrm{mo}, 6-12 \mathrm{mo},>12 \mathrm{mo}$ ); children $\leq 18$ years at home; dog ownership; and number of household cars $(\leq 1,2, \geq 3)$. Health and behavioral variables included self-reported health status ( $1=$ "poor" and 5="excellent"); smoking status; height and weight (converted into body mass index, $\mathrm{kg} / \mathrm{m}^{2}$ ); fruit and vegetable intake; sedentary behavior (hours per day spent watching television, reading, or playing video games); and meeting the 2008 Physical Activity Guidelines prior to moving to Mueller. ${ }^{27}$

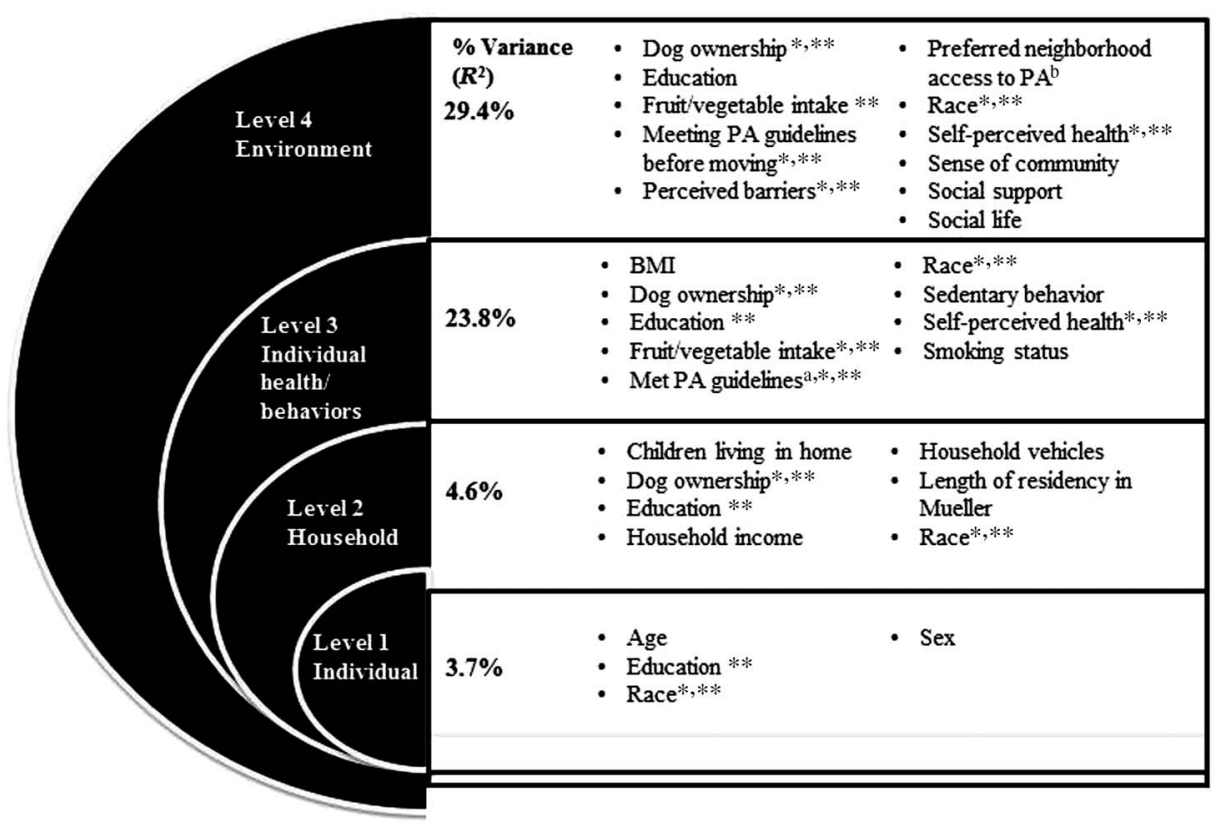

Figure 1 - Hierarchical multiple regression predicting postmove total PA. BMI indicates body mass index; PA, physical activity. ${ }^{\mathrm{a} M e t} 2008$ Physical Activity Guidelines before moving to Muller. ${ }^{b}$ Defined by closeness to parks, recreational facilities, and ease of walking. *Significant contributor $P$ value $\leq .05$. $* * P$ value $<.20$ 


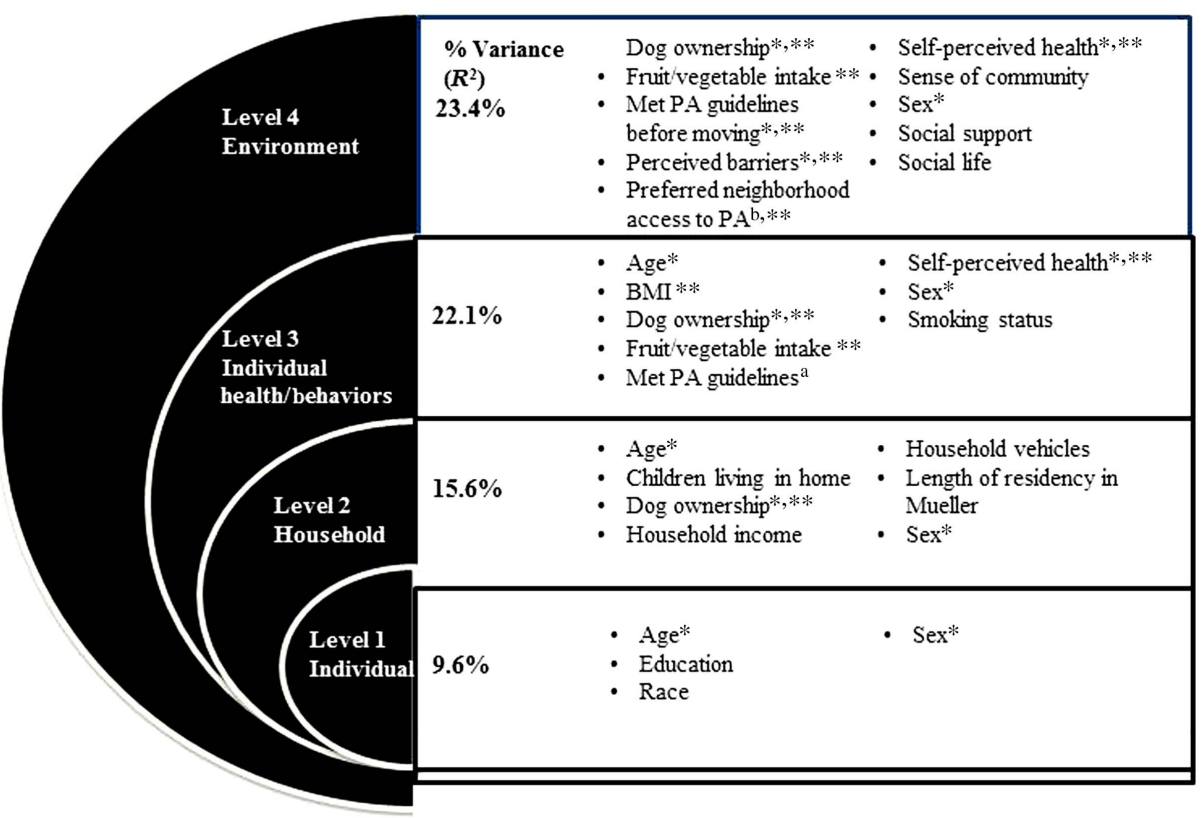

Figure 2 - Hierarchical multiple regression predicting walking for recreation inside the neighborhood. BMI indicates body mass index; PA, physical activity. ${ }^{a}$ Met 2008 Physical Activity Guidelines before moving to Muller. ${ }^{b}$ Defined by closeness to parks, recreational facilities, and ease of walking. *Significant contributor $P$ value $\leq .05$. ** $P$ value $<.20$.

\section{Psychosocial and Environmental Variables.}

(1) Social Support. Respondents answered 5 questions regarding social support $(1=$ "strongly disagree" and $4=$ "strongly agree") including general social support and encouragement from friends and family. Responses to each of the 5 questions were dichotomized as (1) strongly or somewhat disagree/no relatives close by or (2) somewhat or strongly agree. The 5 responses were added together, resulting in scale scores ranging from 0 to 5 , which then were divided into 3 groups: low (0-1), intermediate (2-3), or high (4-5) levels of social support.

(2) Perceived Barriers. Respondents reported how often each of 9 barriers (eg, not having time, feeling tired, and not having a safe place to exercise) kept them from participating in physical activity ( $1=$ "never" and $5=$ "very often"). The scores were combined to create scale scores of 1 to 45 , with higher scores indicating greater perceived barriers. Recoding produced 3 categories : low (9-16), intermediate (17-21), and high (22-45).

(3) Social Life in Neighborhood. Respondents were asked about their interactions with neighbors during the past week. Neighbors were defined as people who live within a 15-minute walking distance. Respondents reported "yes" or "no" on each of 8 different interactions (eg, wave to a neighbor, stop and talk with a neighbor, and have a neighbor at your house to socialize). The reported interactions were added to create scale scores ranging from 0 to 8 , which were then divided into 3 groups: low (0-3), intermediate (4-6), and high (7-8) levels of social life in the neighborhood.

(4) Sense of Community. Respondents reported if living in their neighborhood gave them a sense of community ( 1 = "strongly disagree" and 4 = "strongly agree"); with recoding, 2 categories were created: disagree (1-2) and agree (3-4).
(5) Neighborhood Access to Physical Activity. Respondents reported the importance of 13 identified reasons for moving to Mueller. Three of these items specifically related to the recreational physical activity (closeness to open space such as parks, ease of walking, and closeness to recreational facilities). Responses to these variables were added to create a neighborhood access variable. The overall score ranged from 0 to 15 , with higher scores indicating that neighborhood access to physical activity was very important. Due to shape of the distribution, the scores were recoded as low (3-12) or high (13-15).

\section{Data Analysis}

All statistical analyses were conducted using STATA SE/11.0 (StataCorp, College Station, TX). Alpha levels were set at .05. Preliminary analyses were performed to ensure there was no violation of the assumption of normality, linearity, multicollinearity, and homoscedasticity. HMR was used given its appropriateness when variance on a criterion variable is being explained by predictor variables that are correlated with each other. ${ }^{28}$ To determine the significance of the relationships between variables, the strength of those relationships, and their explanatory power across levels, each variable was entered into the model (without further recoding beyond what was described in the "Methods" section), starting with sex, age, education, and race. Level 2 included household income, length of residency in Mueller, children, dog ownership, and household vehicles. Level 3 included self-perceived health, smoking status, body mass index, fruit and vegetable intake, sedentary behavior, and meeting physical activity guidelines before moving to Mueller. Level 4 included social support, perceived barriers, social life in neighborhood, sense of community, and preferred neighborhood access to physical activity. The variables were entered into the model by level. Predictor tests were conducted in the regression models, and variables with a $P$ value $<.20$ were carried into the next level. 


\section{Results}

Participant characteristics are shown in Table 1. Women represented $61.7 \%$ of the sample. A little less than half (46.0\%) of the sample was 40 years or older $(11.0 \%, \geq 60$ y of age $) ; 93.2 \%$ had graduated from college and $88.6 \%$ were white. Nearly, $45.0 \%$ of the respondents reported a household income greater or equal to $\$ 90,000$, and $43.8 \%$ owned a dog. Almost $35 \%$ perceived their health to be excellent, $24.5 \%$ reported sedentary behavior 4.0 or more hours per day, and $84.6 \%$ met the 2008 Physical Activity Guidelines after moving to Mueller. On average, respondents engaged in 160 minutes per week walking for recreation inside Mueller, up from 92 minutes of walking inside their previous neighborhood.

Psychosocial and environmental characteristics are reported by gender in Table 2. Of note, women reported higher levels of social support and social life in Mueller than men did. Similarly, a higher percentage of women compared with men had a sense of community in Mueller ( $73.8 \%$ vs $59.8 \%$, respectively) and attached a high level of importance to neighborhood access to physical activity. Yet, a higher percentage of men (48.0\%) compared with women $(29.8 \%)$ were in the low perceived barriers group.

\section{Total Physical Activity}

Hierarchical multiple regressions were performed to investigate the ability of individual and household characteristics, health and behaviors, and environmental factors to predict postmove total physical activity (in mean minutes per week). In the first level, 4 predictors were entered: age, education, race, and sex. This model was statistically significant $\left(F_{6,217}=2.42 ; P=.03\right)$ and explained $3.7 \%$ of the variance in postmove total physical activity. Race made a significant unique contribution to the model $(P=.01)$. The second model, which included the household characteristics, accounted for $4.6 \%$ of the variance $\left(F_{13,210}=1.83 ; P=.04\right)$. In addition to race, dog ownership was a significant contributor to total physical activity $(P=.03)$.

\section{Table 1 Reported Participant Characteristics}

\begin{tabular}{|c|c|c|c|}
\hline Characteristics & in $\%$ & Characteristics & in \% \\
\hline Sex & & Dog ownership & \\
\hline Male & 38.3 & No & 56.2 \\
\hline Female & 61.7 & Yes & 43.8 \\
\hline Age, y & & Household vehicles, \# & \\
\hline $20-39$ & 54.1 & $\leq 1$ car & 34.2 \\
\hline $40-59$ & 35.4 & 2 cars & 57.0 \\
\hline$\geq 60$ & 10.5 & $\geq 3$ cars & 8.8 \\
\hline Education & & Self-perceived health & \\
\hline Less than college & 6.8 & Fair/average & 15.3 \\
\hline College & 45.8 & Good & 50.2 \\
\hline Postgraduate & 47.4 & Excellent & 34.5 \\
\hline Race & & Smoking status & \\
\hline White & 88.6 & Never smoked & 64.6 \\
\hline Non-White & 11.4 & Current or former smoker & 35.4 \\
\hline Income & & BMI $\left(\mathrm{k} / \mathrm{m}^{2}\right)$ & \\
\hline$<40,000$ & 10.9 & $<25.0$ & 57.7 \\
\hline $40-59,999$ & 19.1 & $25.0-29.9$ & 32.2 \\
\hline $60-89,999$ & 15.4 & $\geq 30.0$ & 10.1 \\
\hline$\geq 90,000$ & 44.9 & Fruit and vegetable intake & \\
\hline Missing/unknown & 9.7 & $<5$ servings/day & 54.0 \\
\hline Residency & & $\geq 5$ servings/day & 46.0 \\
\hline $1-5 \mathrm{mo}$ & 12.2 & Fat intake & \\
\hline $6-11 \mathrm{mo}$ & 28.6 & Diet high in fat & 9.4 \\
\hline$\geq 12 \mathrm{mo}$ & 59.2 & Diet moderate in fat & 52.5 \\
\hline Children $\leq 18$ y at home & & Diet low in fat & 38.1 \\
\hline None & 72.5 & Sedentary behavior $(\mathrm{h} / \mathrm{d})$ & \\
\hline \multirow[t]{6}{*}{$\geq 1$} & 27.5 & $0.0-1.99$ & 28.0 \\
\hline & & $2.0-3.99$ & 47.5 \\
\hline & & $\geq 4.0$ & 24.5 \\
\hline & & Meets 2008 Physical Activity Guidelines ${ }^{a}$ & \\
\hline & & No & 15.5 \\
\hline & & Yes & 85.6 \\
\hline
\end{tabular}

\footnotetext{
${ }^{\mathrm{a}}$ Adults should do at least $150 \mathrm{~min}(2 \mathrm{~h}$ and $30 \mathrm{~min})$ a week of moderate-intensity, $75 \mathrm{~min}(1 \mathrm{~h}$ and $15 \mathrm{~min})$ a week of vigorous-intensity aerobic activity, or an equivalence combination of moderate- and vigorous-intensity aerobic activity.
} 
Table 2 Psychosocial and Environmental Characteristics by Gender

\begin{tabular}{lcc}
\hline Characteristics & Men $(\mathbf{n}=\mathbf{1 0 0}), \%$ & Women $\mathbf{n}=\mathbf{1 5 6}), \%$ \\
\hline Social support & & \\
Low & 44.4 & 28.9 \\
Intermediate & 46.5 & 55.1 \\
High & 9.1 & 16.0 \\
Perceived barriers & & \\
Low & 48.0 & 29.8 \\
Intermediate & 33.0 & 40.5 \\
High & 19.0 & 29.7 \\
Social life in neighborhood & \\
Low & 43.1 & 27.2 \\
Intermediate & 30.4 & 44.3 \\
High & 26.5 & 28.5 \\
Sense of community in Mueller & \\
Disagree & 40.2 & 26.2 \\
Agree & 59.8 & 73.8 \\
Neighborhood access to physical activity & \\
Low & 56.9 & 49.1 \\
High & 43.1 & 50.9 \\
\hline
\end{tabular}


of walking.

The third model included individual health and behaviors and explained $23.9 \%$ of the variance of postmove total physical activity $\left(F_{13,197}=6.10 ; P<.001\right)$. Self-perceived health $(P=.001)$, fruit and vegetable intake $(P=.05)$, and meeting physical activity guidelines before moving to Mueller $(P<.001)$ were significant contributors to the model. The final model included the environmental factors and accounted for $29.4 \%$ of the variance in postmove total physical activity $\left(F_{16,187}=6.29 ; P<.001\right)$. Perceiving there to be few barriers was a significant contributor to total physical activity $(P=.01)$.

In summary, the final model showed significant associations to postmove total physical activity with being white, owning a dog, better self-perceived health, fruit and vegetable intake, meeting physical activity guidelines before moving to Mueller, and perceiving fewer barriers (all $P \mathrm{~s}<.05$ ) (Figure 1).

\section{Walking for Recreation}

Hierarchical multiple regressions were also performed to investigate factors that predict walking for recreation inside the neighborhood. In the first level, 4 predictors were entered: age, education, race, and sex. This model was statistically significant $\left(F_{6,237}=5.30 ; P<.001\right)$ and explained $9.6 \%$ of the variance in walking for recreation inside Mueller. The second model, which included household characteristics, accounted for $15.6 \%$ of the variance $\left(F_{13,232}=4.50 ; P=.16\right)$. In addition to sex and age, dog ownership was a significant contributor to walking for recreation $(P<.001)$. The third model included individual health and behaviors and explained $22.2 \%$ of the variance of walking for recreation inside Mueller $\left(F_{13,214}=5.98\right.$; $P<.001)$. Sex, age, and dog ownership continued to be significant contributors to walking for recreation in Mueller.

The fourth model included environmental variables and accounted for $23.4 \%$ of the variance in walking for recreation inside the neighborhood $\left(F_{19,200}=4.36 ; P<.001\right)$. In this model, perceiving there to be few barriers was a significant contributor to walking inside Mueller for recreation $(P=.03)$.

In summary, the final model showed significant associations to walking with being female, being older, owning a dog, and perceiving fewer barriers to physical activity (all $P_{\mathrm{s}}<.05$ ) (Figure 2 ).

\section{Discussion}

The present study is the first of which we are aware that has examined sources of variation in total physical activity and a behavior-specific activity (ie, walking for recreation inside one's neighborhood). The overall predictors of total physical activity were different than those of walking for recreation, with the exception of dog ownership and perceived barriers. Associations between the environment and physical activity become clearer when examining a specific behavior like walking inside the neighborhood for recreation rather than total physical activity. Our data show having access to physical activity amenities (ie, ease of walking and closeness to parks and recreational facilities) was very important in the respondents' decision to move to Mueller. Women reported higher levels of social support and social life in Mueller than did men. Similarly, a higher percentage of women compared with men had a sense of community in Mueller. Although physical activity participation is consistently higher among men than in women and declines with age, ${ }^{9}$ women and older adults walked more for recreation in Mueller (and thus engaged in more total physical activity) compared with men and younger adults. Gender and age were significant predictors of walking for recreation, but these associations did not hold when looking at total physical activity.

This interpretation is consistent with other studies that suggest women appear more likely than men to walk for physical activity ${ }^{19,29}$ and engage in physical activities in their neighborhood. ${ }^{19}$ Velasquez et $\mathrm{al}^{30}$ found leisure-time physical activity and meeting physical activity recommendations among women to be associated with the use of community walking trails, parks, playgrounds, or sports fields and with use of public recreation centers. Brownson et $\mathrm{al}^{31}$ found that women were more than twice as likely as men to have increased their walking since they began using local trails. Humpel et $\mathrm{al}^{17}$ found women who perceived their neighborhood to be a convenient place to walk had higher levels of neighborhood walking. Yet, there are inconsistencies across other studies which may be explained in part by the choice of exposure measures. Our study found varying levels of influence across total physical activity and walking for recreation. Looking at contextual factors and specific physical activity behaviors, as well as total physical activity, rather than just one or the other is important in the development of effective policies and interventions.

Dog ownership and perceived barriers were predictors of total physical activity and walking for recreation inside the neighborhood. These results are consistent with other studies, ${ }^{15,25,32}$ including several studies which also found dog ownership to be associated with physical activity in later life. ${ }^{33-35}$ Two possible explanations are that dogs provide owners with motivation to walk $\mathrm{k}^{32}$ or facilitate and increase social interaction. $\mathrm{Wu}$ et $\mathrm{ll}^{35}$ found that dog owners showed a smaller decline in the number of steps on days with inclement weather. Furthermore, compared with nondog owners or nondog walkers, dog owners were more active on the coldest and hottest days. This is particularly interesting given that poor weather is a commonly cited barrier to physical activity. ${ }^{36}$ Although we cannot specifically say 
that owning a dog enabled respondents to overcome weatherrelated barriers in terms of their physical activity levels, our study found that respondents reporting few barriers were the most active. This finding suggests the potential importance of companion dogs in providing emotional and instrumental support that promotes regular physical activity among older adults. Additional studies should be conducted to further investigate the role that dogs may have in increasing physical activity levels, particularly one's ability to overcome weather-related barriers among the aging population.

Neighborhood features were a predictor of total physical activity and walking for recreation inside the neighborhood. Although the strength of that predictive relationship was reduced, once other individual, psychosocial, and environmental variables were considered. Nonetheless, several assumptions can be made regarding the higher levels of physical activity found among older women, compared with males and younger adults. The hierarchical approach to these multilevel relationships offers the estimation of regression coefficients across scales, or levels, in addition to partitioning variation. Every relationship identified took into account the scale, or level, of the pattern explained. HMR was chosen over stepwise regression because the order of variable entry into the analysis is based on theory, and it does not have the same drawbacks regarding degrees of freedom, identification of best predictor set of a prespecified size, and replicability. ${ }^{37}$ It proved useful to look at the contributions of predictors above and beyond those previously entered, as a means of statistical control.

This study is subject to several limitations. All information is self-reported, susceptible to recall and social desirability bias. Although the Neighborhood Physical Activity Questionnaire has been found to be reliable, the validity is unknown. However, Neighborhood Physical Activity Questionnaire was based on the International Physical Activity Questionnaire, a validated instrument. In addition, there were overall high levels of activity reported (results published elsewhere) ${ }^{14}$ which may reflect a response bias. Households with active adults may have been more likely to return surveys than households with inactive adults. The sample was homogeneous, and the extent to which these findings are generalizable to other populations is unknown. Finally, the data were collected several years ago. Nevertheless, these findings are important now; not only are mixed-use neighborhoods such as Mueller being established across the country, our population is aging. Increasing knowledge pertaining to factors associated with total physical activity and walking for recreation within such neighborhoods, and among older adults, is important. At this point in time, our findings suggest different factors are associated with walking for recreation compared with total physical activity, with the exception of perceived barriers and dog ownership. There are a number of combinations of variables that could be introduced within (eg, individual level) and across the ecological model (eg, individual and community) and should be studied.

\section{Conclusion}

Our analysis demonstrated that focusing on behavior-specific physical activity as well as total physical activity led to a better understanding of factors that may impact behavior among baby boomers and an overall aging population, especially women. This level of specificity is important in developing cost-effective and efficient policies and interventions. Similar research should be done to further explore behavior-specific physical activity as well as combinations of variables in other, more diverse communities.

\section{References}

1. Department of Health and Human Services Administration on Aging. A Profile of Older Americans. Administration on Aging, Administration for Community Living U.S. Department of Health and Human Services; 2014. https://www.acl.gov/sites/default/files/Aging\%20and \%20Disability\%20in\%20America/2014-Profile.pdf

2. Colby SL, Ortman JM. The Baby Boom Cohort in the United States: 2012 to 2060. U.S. Department of Commerce Economcis and Statistics Administration. United States Census Bureau; 2014. https://www. census.gov/prod/2014pubs/p25-1141.pdf

3. King DE, Matheson E, Chirina S, Shankar A, Broman-Fulks J. The status of baby boomers' health in the United States: the healthiest generation? JAMA Intern Med. 2013;173(5):385-386. PubMed ID: 23381505 doi:10.1001/jamainternmed.2013.2006

4. U.S. Department of Health and Human Services. 2008 Physical Activity Guidelines for Americans. Hyattsville, MD: U.S. Department of Health and Human Service; 2008. http://www.health.gov/paguidelines

5. Lee IM, Buchner DM. The importance of walking to public health. Med Sci Sports Exerc. 2008;40(suppl 7):S512-S518. PubMed ID: 18562968 doi:10.1249/MSS.0b013e31817c65d0

6. Centers for Disease Control and Prevention. Vital signs: walking among adults-United States, 2005 and 2010. MMWR Morb Mortal Wkly Rep. 2012;61:595-601. PubMed ID: 22874838

7. Richardson CR, Newton TL, Abraham JJ, Sen A, Jimbo M, Swartz AM. A meta-analysis of pedometer-based walking interventions and weight loss. Ann Fam Med. 2008;6(1):69-77. PubMed ID: 18195317 doi:10.1370/afm.761

8. Lee LL, Watson MC, Mulvaney CA, Tsai CC, Lo SF. The effect of walking intervention on blood pressure control: a systematic review. Int J Nurs Stud. 2010;47(12):1545-1561. PubMed ID: 20863494 doi:10.1016/j.ijnurstu.2010.08.008

9. Sun F, Norman IJ, While AE. Physical activity in older people: a systematic review. BMC Public Health. 2013;13:449. PubMed ID: 23648225 doi:10.1186/1471-2458-13-449

10. Nehme EK, Oluyomi AO, Calise TV, Kohl HW 3rd. Environmental correlates of recreational walking in the neighborhood. Am J Health Promot. 2016;30(3):139-148. PubMed ID: 25615703 doi:10.4278/ ajhp.130531-QUAN-281

11. Cohen L, Chavez V, Chehimi S. Prevention is primary: Strategies for community well-being. Oakland, CA: Prevention Institute; 2007.

12. Sallis JF, Owen N. Ecological models of health behavior. In: Glanz K, Rimer BK, Lewis FM, eds. Health Behavior and Health Education: Theory, Research, and Practice. 3rd ed. San Francisco, CA: JosseyBass; 2002:462-484.

13. Elder JP, Lytle L, Sallis JF, et al. A description of the socialecological framework used in the trial of activity for adolescent girls (TAAG). Health Educ Res. 2007;22(2):155-165. PubMed ID: 16855014 doi:10.1093/her/cyl059

14. Calise TV, Dumith SC, DeJong W, Kohl HW 3rd. The effect of a neighborhood built environment on physical activity behaviors. J Phys Act Health. 2012;9(8):1089-1097. PubMed ID: 22207103 doi:10.1123/jpah.9.8.1089

15. Ball K, Bauman A, Leslie E, Owen N. Perceived environmental aesthetics and convenience and company are associated with walking for exercise among Australian adults. Prev Med. 2001;33(5): 434-440. PubMed ID: 11676585 doi:10.1006/pmed.2001.0912

16. Cleland VJ, Timperio A, Crawford D. Are perceptions of the physical and social environment associated with mothers' walking for leisure and for transport? A longitudinal study. Prev Med. 2008;47(2):188-193. PubMed ID: 18584859 doi:10.1016/j. ypmed.2008.05.010 
17. Humpel N, Owen N, Leslie E, Marshall AL, Bauman AE, Sallis JF. Associations of location and perceived environmental attributes with walking in neighborhoods. Am J Health Promot. 2004;18(3):239-242. PubMed ID: 14748314 doi:10.4278/0890$1171-18.3 .239$

18. Cao X, Handy SL, Mokhtarian P. The influences of the built environment and residential self-selection on pedestrian behavior: evidence from Austin, TX. Transportation. 2006;33:1-20.

19. Suminski RR, Poston WS, Petosa RL, Stevens E, Katzenmoyer LM. Features of the neighborhood environment and walking by U.S. adults. Am J Prev Med. 2005;28(2):149-155. PubMed ID: 15710269 doi:10.1016/j.amepre.2004.09.009

20. De Bourdeaudhuij I, Teixeira PJ, Cardon G, Deforche B. Environmental and psychosocial correlates of physical activity in Portuguese and Belgian adults. Public Health Nutr. 2005;8(7):886-895. PubMed ID: 16277805 doi:10.1079/PHN2005735

21. Sugiyama T, Leslie E, Giles-Corti B, Owen N. Physical activity for recreation or exercise on neighbourhood streets: associations with perceived environmental attributes. Health Place. 2009;15(4): 1058-1063. PubMed ID: 19473867 doi:10.1016/j.healthplace. 2009.05.001

22. Sugiyama T, Shibata A, Koohsari MJ, et al. Neighborhood environmental attributes and adults' maintenance of regular walking. Med Sci Sports Exerc. 2015;47(6):1204-1210. PubMed ID: 25251048 doi:10. 1249/MSS.0000000000000528

23. Giles-Corti B, Timperio A, Bull F, Pikora T. Understanding physical activity environmental correlates: increased specificity for ecological models. Exerc Sport Sci Rev. 2005;33(4):175-181. PubMed ID: 16239834 doi:10.1097/00003677-200510000-00005

24. Craig CL, Marshall AL, Sjostrom M, et al. International physical activity questionnaire: 12-country reliability and validity. Med Sci Sports Exerc. 2003;35(8):1381-1395. PubMed ID: 12900694 doi:10. 1249/01.MSS.0000078924.61453.FB

25. Cutt H, Giles-Corti B, Knuiman M, Burke V. Dog ownership, health and physical activity: a critical review of the literature. Health Place. 2007;13(1):261-272. PubMed ID: 16503185 doi:10.1016/j. healthplace.2006.01.003

26. Department of Health and Human Services. 2008 Physical Activity Guidelines for Americans. Washington, DC: U.S. Department of Health and Human Services; 2008.
27. U.S. Department of Health and Human Services. Physical Activity Guidelines Advisory Committee Report, 2008. Hyattsville, MD: U.S. Department of Health and Human Services; 2008. http://www.health. gov/paguidelines

28. Pedhazur EJ. Multiple Regression in Behavioral Research: Explanation and Prediction. 3rd ed. Fort Worth, TX: Harcourt Brace; 1997.

29. Abel T, Graf N, Niemann S. Gender bias in the assessment of physical activity in population studies. Soz Praventivmed. 2001;46(4): 268-272. PubMed ID: 11582854 doi:10.1007/BF01593182

30. Velasquez KS, Holahan CK, You X. Relationship of perceived environmental characteristics to leisure-time physical activity and meeting recommendations for physical activity in Texas. Prev Chronic Dis. 2009;6(1):A24. PubMed ID: 20712932

31. Brownson RC, Housemann RA, Brown DR, et al. Promoting physical activity in rural communities: walking trail access, use, and effects. Am J Prev Med. 2000;18(3):235-241. PubMed ID: 10722990 doi:10.1016/S0749-3797(99)00165-8

32. Lim C, Rhodes E. Sizing up physical activity: the relationship between dog characteristics, dog owners' motivations, and dog walking. Psychol Sport Exerc. 2016;24:65-71. doi:10.1016/j. psychsport.2016.01.004

33. Feng Z, Dibben C, Witham MD, et al. Dog ownership and physical activity in later life: a cross-sectional observational study. Prev Med. 2014;66:101-106. PubMed ID: 24931433 doi:10.1016/j.ypmed.2014. 06.004

34. Dall PM, Ellis SLH, Ellis BM, et al. The influence of dog ownership on objective measures of free-living physical activity and sedentary behaviour in community-dwelling older adults: a longitudinal casecontrolled study. BMC Public Health. 2017;17(1):496.

35. Wu XY, Han LH, Zhang JH, Luo S, Hu JW, Sun K. The influence of physical activity, sedentary behavior on health-related quality of life among the general population of children and adolescents: a systematic review. PLoS One. 2017;12(11):e0187668. PubMed ID: 29121640 doi:10.1371/journal.pone.0187668

36. Tucker P, Gilliland J. The effect of season and weather on physical activity: a systematic review. Public Health. 2007;121(12):909-922. PubMed ID: 17920646 doi:10.1016/j.puhe.2007.04.009

37. Lewis M. Stepwise versus hierarchical regression: pros and cons. Paper presented at the annual meeting of the Southwest Educational Research Association; February 7, 2007. San Antonio, TX. 